\title{
Two prototypes for medium rotation forestry harvesting
}

\author{
L. Pari, V. Civitarese, A. Del Giudice, A. Scarfone \\ Consiglio per la Ricerca e la Sperimentazione in Agricoltura, Unità di Ricerca per l'Ingegneria \\ Agraria, Monterotondo (Roma), Italy
}

\section{Abstract}

Five years old poplar (Populus spp.) plantation represents an interesting model of productivity. The most attractive characteristics of this energy crop are the handling flexibility, the high yield of biomass per area unit and the good quality of the chips obtainable.

The mechanical harvesting of five-years old poplar plantations requires the use of specialized forest machineries such as harvester, feller, forwarder and chipper. Usually, after felling, the working phases consist of extraction, stacking and chipping. Generally, the last one is carried out in a "static phase", where the product is taken from staked logs by using a hydraulic arm having a gripper that feed the chipping machine.

In order to introduce technological innovations for the medium rotation forestry harvesting, the Consiglio per la Ricerca e la sperimentazione in Agricoltura, Unità di ricerca per l'Ingegneria agraria (CRAING) of Monterotondo (Rome, Italy) has developed a five years poplar cutwindrower and a self-propelled chipper equipped with a pick up system.

The prototype of cut-windrower is a semi-trailed machine powered by a $95 \mathrm{~kW}$ tractor (at least). It mounts a cutting system and a double pincer with variable positioning. During the cutting phase the plant is grasped by the double pincer which conveys and unloads the stem along the inter-row. The trees are placed parallel to the progress of the tractor, but oriented in the opposite direction.

The biomass windrowed is then chipped in a dynamic phase directly from the inter row using the self-propelled chipper equipped with the pick-up head.

In the first tests, the cut-windrower has reached an operative working capacity of $0.22 \mathrm{ha} \mathrm{h}^{-1}$, with an operative production of $44 \mathrm{t} \mathrm{h}^{-1}$. On the other hand, the self-propelled chipper has showed an operative working capacity equal to $0.18 \mathrm{ha} \mathrm{h}^{-1}$, and an operative production of $35 \mathrm{t} \mathrm{h}^{-1}$ about.

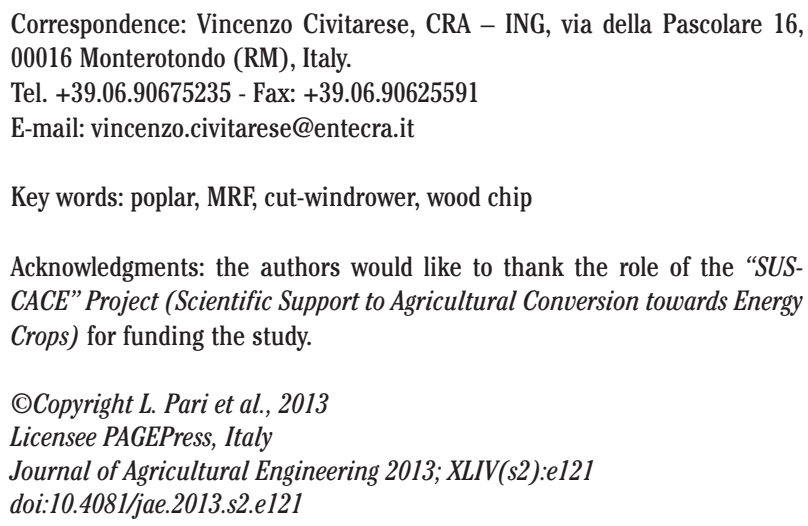

Acknowledgments: the authors would like to thank the role of the "SUSCACE" Project (Scientific Support to Agricultural Conversion towards Energy Crops) for funding the study.

@C Copyright L. Pari et al., 2013

Licensee PAGEPress, Italy

Journal of Agricultural Engineering 2013; XLIV(s2):e121

doi:10.4081/jae.2013.s2.e121

This article is distributed under the terms of the Creative Commons Attribution Noncommercial License (by-nc 3.0) which permits any noncom-
Both machines have shown good quality of the work performed and the results obtained indicates that the work phases could be simplified in order to reduce both the time of use and the harvesting costs.

\section{Introduction}

Short-rotation coppice crops (SRCs) are an important resource that can be used as renewable energy (Hansen, 1991; Zamora et al., 2013), and a possible alternative to fossil fuels in Europe (Bergante et al., 2010).

The Italian climatic conditions can be considered optimal for growing poplar tree (Paris et al., 2011) which is one of the most important species for the biomass production. New poplar hybrids and cultivars specifically selected by Italian researcher have showed in experimental trials a very high production capacity (Dillen et al., 2007).

Among the different cropping system, the five years old poplar (Populus spp.) plantation represents a productive model very interesting for its handling flexibility, big yield and good chips quality. The planting distance $(3 \times 2 \mathrm{~m})$ and the dimension reached by plant at end of the productive cycle (average basal diameter of 180-200 mm, average height of $15 \mathrm{~m}$ ) can justify the presence of a forestry yard (Spinelli et al., 2008) organized in compliance with the plants size, the field extension and the productive purpose (Spinelli et al., 2006).

In traditional yard, the trees after felling are generally stacked in designated areas (eg. field sideline) and then chipped by specific machines (trailed or self-propelled chippers) fed by a log grape.

The Engineering unit of the Agricultural Research Council (CRAING) of Monterotondo (Rome, Italy) has developed a new harvesting chain for the harvest of five years old poplar plantation.

In this chain the plants are felled, windrowed, and then chipped in a dynamic phase using a prototype of cut windrower (powered by a tractor of $95 \mathrm{~kW}$ at least) and a self-propelled chipper equipped with a pick-up head.

The yard proposed and the machines developed for the harvest of five-year old poplar plantations may represent an important innovation for the mechanization of the energy crops. Beside the simplification and the reduction of the harvesting time, this new chain allows to reduce harvesting time and cost, increasing also the number of working hours of tractors. The innovative system was studied by analysing the performance and the quality of the work performed by the new machines during the collection of five years old poplar plantation.

\section{Prototype description}

The cut-windrower (Table 1) is a semi-trailed machine having a mass of $2046 \mathrm{~kg}$. The main components of the machine are the cutting system and the double pincer. The double pincer performs different functions such as gripping, transport and unload. The machine is able to cut and leave the plants along the inter-row par- 
allel to the progress of the tractor. Once released on the ground, the trees appears with the crowns oriented in the opposite direction respect the advancement of the machine (Fig. 1). The cutting system consists of a sawblade ( $1000 \mathrm{~mm}$ in diameter) that cuts at $2200 \mathrm{rpm}$. It is installed on a mobile support connected to a spring capable to absorb part of the stress occurred during cutting. The cut-windrower has two wheels that held the machine during work and allow to adjust the cutting height by the action of two jacks (the minimum cut height is $50 \mathrm{~mm}$ ). The double pincer is composed by two series of mechanic arms (gripping elements) which can be partially overlapped and capable to spin around a master rotary column. When the pincer come s into contact with the tree, it begins to perform a series of operations following a defined time model. These operations consist in griping, lifting, transport toward the inter-row, inclination, release of the plant, and return to the original position.

The time scheduled for opening and tilt of the pincer can be modified with a specific command.

Table 1. technical characteristics of the five years old cut-windrower machine.

\begin{tabular}{lc} 
Cut windrower machine & $3.21 \times 3.60$ \\
Width and length in working phase (m) & $2.35 \times 3.60$ \\
Width and length in transporting phase (m) & 2.8 \\
\hline Maximum height (m) & 2046 \\
Total mass (Kg) & 1000 \\
\hline Cutting system & 12 \\
Diameter of the circular blade (mm) & 36 \\
\hline Circular blade and tooth thickness (mm) & 2200 \\
Tooth (N $)$ & 50 \\
\hline Rotation speed (rpm/min) & \\
Minimum cut height (mm) & 2 \\
\hline Adjustable double pincer & 795 \\
Mechanic arms $\left(\mathrm{N}^{\circ}\right)$ & 5 \\
\hline Gripping extent on the trunk (mm) & \\
Working phases $\left(\mathrm{N}^{\circ}\right)$ & \\
\hline
\end{tabular}

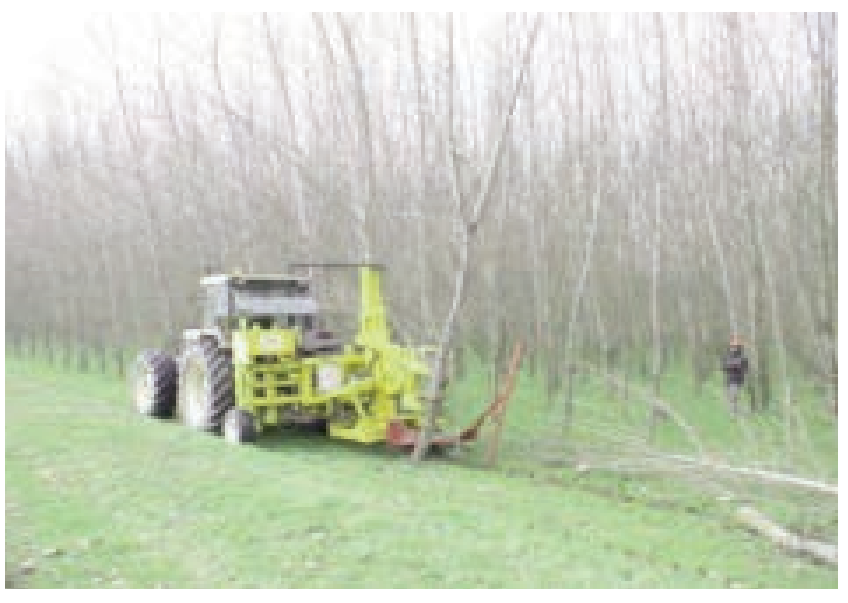

Figure 1. Cut windrower machine during the placement of trees on windrow.
The cutting tool and the pincer are able to move laterally from the primary body of the machine, going from the transport configuration to the working configuration.

The self-propelled machine is driven by a 6 cylinders endothermic diesel engine of Iveco FPT (Fiat Powertrain Technologies), with a maximum power of $260 \mathrm{~kW}$. The machine is equipped with four isodiametric wheels (500/18 R22 tires) and the transmission is designed with different driving systems that depending on the needs can be varied using an electric command placed in the cab. The driving configurations are the following: front steering and fixed rear wheels, four-wheel steering, side tractor shift, crab movement.

The machine has a maximum length, width and height of $6390 \mathrm{~mm}$, $2510 \mathrm{~mm}$ and $3910 \mathrm{~mm}$ respectively, a total weight of $9250 \mathrm{~kg}$, with a tank containing about 300 liters of fuel.

The prototype has a reversible drive, with a tipper for loading having the capacity of $15.7 \mathrm{~m} 3$. In order to unload the product directly on the trailers of trucks, the tipper is hinged onto the outer frame of the machine to a height of $3910 \mathrm{~mm}$. Finally, the machine presents frontally the PTO and two arms to connect respectively to the chipping device and to the pick up head.

The chipping system is designed to comminute trees up to a maximum diameter of $380 \mathrm{~mm}$. It consists of a disc with diameter and thickness of $1600 \mathrm{~mm}$ and $60 \mathrm{~mm}$ respectively working at a speed of 1000 rpm. The disk is directly connected to the PTO by a shaft and two radial blades operate the cut with a fix counter-knife.

The pick-up device consists of a rotary cylinder having diameter and length of $155 \mathrm{~mm}$ e $1750 \mathrm{~mm}$ respectively. The rotary cylinder has 105 steel reliefs, each one $70 \mathrm{~mm}$ long. This tool has both gripping and lifts functions; its rotational axis is $820 \mathrm{~mm}$ distant from the power supply system of the machine, presenting a space of $370 \mathrm{~mm}$ for unloading impurities.

The conveyor system is implemented by two groups of three counterrotating toothed drums, which help to direct the material toward the chipping apparatus. Each drum has a diameter of $250 \mathrm{~mm}$ and a height of $700 \mathrm{~mm}$.

Moreover, the chipping supply system has two vertical counter-rotating drums, one fixed, the other mobile, whose motion depends on the size of the product. A hydraulic system is installed on the two sides of the pick up head; this allows the contact between the collecting organ and the ground.

During the progress along rows, the self-propelled prototype combined with the pick-up head has been capable to harvest and chipping

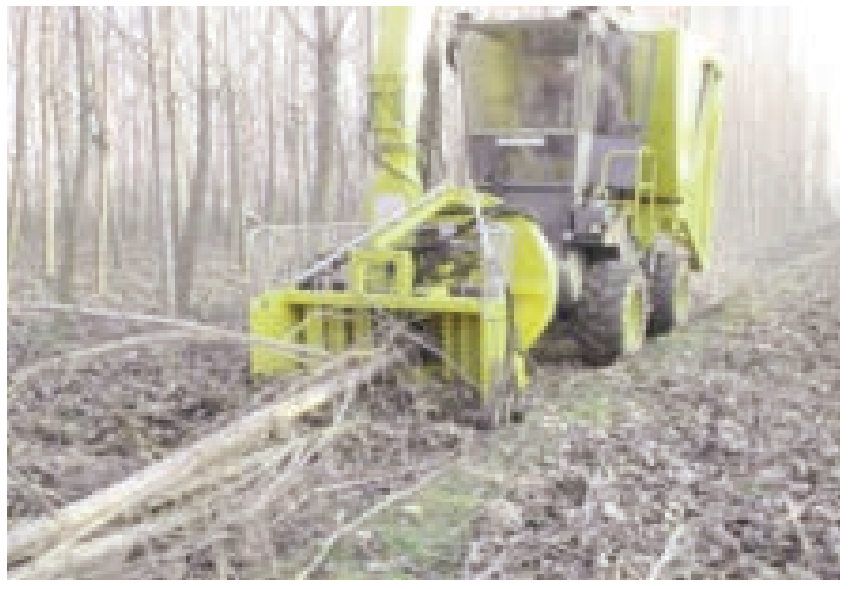

Figure 2. Self propelled chipper during the harvest. 
trees from the ground, as well as to unload the product on the rear tipper of the machine (Fig. 2) or on trailers.

\section{Materials and methods}

Machines performance and work quality were analyzed on three rows (160 m length each) of five years poplar plantation (planting distance $3 \times 2 \mathrm{~m}$, plant density 1666 plants $^{-1}$ ) at the first coppice cycle (root and stem five-years old: R5S5). The harvesting trial was carried out during January 2012 in Savigliano (CN - Italy).

The average height and the diameter of the plants have been evaluated on 30 samples randomly distributed throughout the test area. The diameters have been measured at $100 \mathrm{~mm}$ from the ground.

The percentage of dead stools was evaluated along the three harvested rows.

The yield of the plantation was assessed weighting the whole biomass chipped after felling.

Standard harvesting times were registered according to the methodology of the Commission Internationale de l'Organisation Scientifique du Travail en Agriculture (C.I.O.S.T.A.).

The parameters considered to evaluate the work quality of the cut windrower were the cutting height, the stump damage, the regularity of windrows, the percentage of plant not correctly placed along the inter-row. On the other hand, the parameters considered for the work quality of the self-propelled chipper were the product losses and the bulk density, the moisture content, and the particle size distribution of the chips obtained.

The cutting height, the stump damage, the percentage of plants not correctly placed along the inter-row, and the product losses were evaluated on three random plots of $30 \mathrm{~m} 2$ from each row.

In particular, the product losses were quantified collecting and weighing all the biomass on the ground after the passage of the selfpropelled chipper. The losses have been classified in two categories:

- plants not collected from the pick up head,

- plants not correctly conveyed in the power supply system.

The bulk density was evaluated measuring the weight of five volumetric cylinder after that the product was unloaded on the ground. Five chip samples of $3 \mathrm{~kg}$ each were collected into sealed bags, catalogued and transported in laboratory for determining the moisture content and the particle size distribution. The entire procedure was done following the standard methodology of the European Standard EN (UNI EN 15103-2009, UNI EN 14774-2009) and the Technical Specifications (CEN/TS 15149-2006).

\section{Results}

The crop was in a good condition of plant health, weeds were almost absent. The average height and diameter of the plants were $18.60 \mathrm{~m}$ (std. dev. \pm 1.74 ) and $189 \mathrm{~mm}$ (std. dev. \pm 30.03 ) respectively. The percentage of leaks was $1.408 \%$ on average, so the real density was 1642 plants ha- ${ }^{-1}$. The harvestable biomass was $198 \mathrm{t} \mathrm{ha}^{-1}$, corresponding to 16.77 odt ha $^{-1}$ year-1 $^{-1}$ (the moisture content of the plants was $57.65 \%$ ) (Table 2).

The felling-windrowing machine (installed on a tractor Fendt 716 Vario TMS $\mathrm{N}$ with a power of $130 \mathrm{~kW}$ ), working at a speed of $0.24 \mathrm{~m} \mathrm{~s}^{-1}\left(0.87 \mathrm{~km} \mathrm{~h}^{-1}\right)$ has achieved an operative working capacity of $0.22 \mathrm{ha} \mathrm{h}^{-1}$ and an operative hourly production of $44 \mathrm{th}^{-1}$.

On the other hand, the self-propelled chipper worked at a speed of $0.18 \mathrm{~m} \mathrm{~s}^{-1}\left(0.65 \mathrm{~km} \mathrm{~h}^{-1}\right)$ achieving an operative working capacity of
$0.18 \mathrm{ha} \mathrm{h}^{-1}$ and an operative hourly production of $35 \mathrm{t} \mathrm{h}^{-1}$. Rest and dead time were not recorded while accessory time was represented by time for turns $(4.36 \%$ for the cut windrowing machine and $6.19 \%$ for the self-propelled chipper) and maintenance time $(9.40 \%$ for the cut windrowing machine and $3.49 \%$ for the self-propelled chipper). Table 3 displays times recorded during the harvesting trials.

The cutting height resulted $119.30 \mathrm{~mm}$ on average (std. dev. \pm 17.13). The percentage of plants not correctly placed along the interrow was equal to the $3 \%$ of the total trees felled.

Table 2. dendrometric parameters registered in the experimental plantation.

\begin{tabular}{lc} 
Inter-row distance (m) & 3 \\
\hline Distance within the plants (m) & 2 \\
Dead stools (\%) & 1.40 \\
\hline Effective density (p ha-1) & 1642 \\
Shoots/coppice (n. ${ }^{\circ}$ ) & 1 \\
\hline Plants diameter (mm) & $189 \square 30.03$ \\
Plants height (m) & $18.60 \square 1.74$ \\
\hline Fresh biomass (t ha-1) & 198 \\
Moisture content (\%) & 57.65 \\
\hline Yield (odt ha-1 year $\left.{ }^{-1}\right)$ & 16.77
\end{tabular}

Table 3. performance of the machines.

\begin{tabular}{lcc} 
& $\begin{array}{c}\text { Cut } \\
\text { windrower }\end{array}$ & $\begin{array}{c}\text { Self propelled } \\
\text { chipper }\end{array}$ \\
Effective speed $\left(\mathrm{m} \mathrm{s}^{-1}\right)$ & 0.24 & 0.18 \\
Operative working capacity $\left(\mathrm{ha} \mathrm{h}^{-1}\right)$ & 0.22 & 0.18 \\
\hline Hourly operative production $\left(\mathrm{t} \mathrm{h}^{-1}\right)$ & 44 & 35 \\
Accessory time (\%) & 13.76 & 9.68 \\
\hline - Time for turns & 4.36 & 6.19 \\
- Maintenance time & 9.40 & 3.49 \\
\hline
\end{tabular}
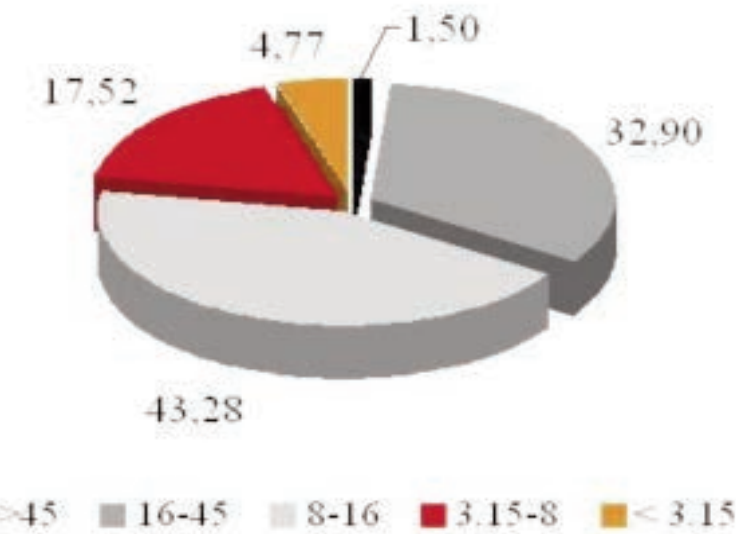

Figure 3. particle size distribution of chips. 
The self-propelled machine was able to pick up and chip the $99.15 \%$ of the windrowed leaf biomass on the ground (1.68 $\mathrm{t}$ representing the $0.85 \%$ of the total).

The chips produced had a bulk density of $293.60 \mathrm{~kg} \mathrm{mc}^{-1}$ (std. dev. \pm 12.48 ) and a moisture content equal to $57.65 \%$.

The particle size analysis has shown that the largest part of the product was concentrated in classes of $8-16 \mathrm{~mm}$ and $16-45 \mathrm{~mm}$, representing respectively the $43.28 \%$ e $32.90 \%$ of the total sampling. Impurities or over measured particles were absent (Fig. 3).

\section{Discussion and conclusions}

The tests carried out have shown the relevant performance and the good work quality of the machines. CRA ING cut windrower prototype has shown a high working speed, processing about 360 trees per hour. The self-propelled chipper has been able to collect the plants from the ground previously felled and left along inter-rows; it has allowed to operate in a dynamic phase. Similarly to the collection of biennial poplar plantations, the chips produced can be unloaded directly on tractor trailers, reducing the number of the working phases.

Finally, these results show the possibility to optimize the logistic of the whole yard, reducing the harvesting time and the general costs.

\section{References}

Bergante S, Facciotto G, Minotta G. Identification of the main site fac- tors and management intensity affecting the establishment of Short-Rotation-Coppices (SRC) in Northern Italy through Stepwise regression analysis. Central European Journal of Biology 2010; 5(4):522-30.

CEN/TS 15149-1:2006. Solid biofuels. Methods for the determination of particle size distribution - Part 1: Oscillating screen method using sieve apertures of $3,15 \mathrm{~mm}$ and above.

Dillen SY, Marron N, Bastien C, Ricciotti L, Salani F, Sabatti M, Pinel MPC, Rae AM, Taylor G, Ceulemans R. Effects of environment and progeny on biomass estimations of five hybrid poplar families grown at three contrasting sites across Europe. Forest Ecology and Management 2007;252(1-3):12-23.

Hansen EA. Poplar woody biomass yields: a look to the future. Biomass and Bioenergy 1991; 1:1-7.

Paris P, Mareschi L, Sabatti M, Pisanelli A, Ecosse A, Nardin F, Scarascia-Mugnozza G. Comparing hybrid Populus clones for SRF across northern Italy after two biennial rotations: Survival, growth and yield. Biomass and Bioenergy 2011;35:1524-32.

Spinelli R., Nati C., Magagnotti N. SRF di pioppo - macchine e sistemi per la raccolta. Sherwood - Foreste ed alberi oggi 2006;128:56-9.

Spinelli R., Nati C., Magagnotti N., Picchi G. Harvesting poplar medium rotation coppice with light equipment. Proceedings of 23th International Poplar Commission (IPC, FA0), Pechino, China; 2008 p.168.

UNI EN 14774-2:2009. Solid biofuels. Determination of moisture content. Oven dry method (Part 2): Total moisture - Simplified method.

UNI EN 15103:2009. Solid biofuels Determination of bulk density.

Zamora DS, Wyatt GJ, Apostol KG, Tschirner U. Biomass yield, energy values, and chemical composition of hybrid poplars in short rotation woody crop production and native perennial grasses in Minnesota, USA. Biomass and Bioenergy 2013;49:222-30. 